\title{
Resolving International Conflict in the Cultural and Identity Context*
}

\author{
Cho, Yun Young \\ (Chung-Ang University)
}

\section{$\langle$ CONTENTS〉}

I. Introduction

II. The Limited Role of Culture and Realism in Cold War era

III. Different Discussions of Culture

IV. Culture as a Core Construct
V. The Relationship between Culture and Conflict

VI. Culture in Conflict Resolution

VII. Conclusion

- Keyword: culture, identity, conflict, international conflict resolution, international negotiation

\section{【ABSTRACT】}

As the ending of the Cold War presents us with a more fragmented world, theory of international relations is growing more aware of its own cultural roots and biases, and so it becoming more sensitive to cultural difference. With the demise of Soviet Union and the bipolar world order, the need to designate "the other" resulted in the specific focus on the difference in cultures of the East and the West, the threat of Islamic fundamentalism and China and the clash of civilizations that characterized "the end of history." On the other hand, due to the globalization of international transactions, people of different cultures were faced with the necessity of negotiating and communicating with one another.

This necessity emanated a range of literature from scholarly to popular writings on getting to know the other cultures and learning different negotiation styles. This paper argues that culture shapes human behavior, attitudes and perceptions as a variable and is, in return, shaped by it through social construction of cultural characteristics. The role of culture in conflict resolution is illuminated in preparing

*This research was supported by the Chung-Ang University Research Grants. 
the specific context for the expression of human needs in conflict situations, behavior and attitudes of both the parties and the mediators involved in conflict resolution.

\section{I . Introduction}

The emergence of ethnic and identity conflict following the collapse of the Cold War attracted salient attention to issues of culture in international conflict resolution. ${ }^{1)}$ But, the proliferation of concern in the issue of culture has not generated its full impact on the research of international relations. As long as the field operates within the confines of the dichotomies of international-domestic realms and structure-agent debates, culture is bound to remain secondary phenomena. This tendency results in an inability to comprehensively understand and explain fundamental aspects of world politics such as the dynamics of inter-state and inter-communal conflicts. Therefore, a dynamic and generic concept of culture and the evolution of an analytical approach which can evaluate the double role of culture as both a variable and a socially constructed outcome in human affairs in general, and in international relations in particular, is necessary.

This paper will discuss limited role of culture in world politics at the Cold War era and different definitions of culture. Then, the double role of culture will be analyzed to understand to the extent to which culture shapes human behavior, attitudes and perceptions as a variable and is, in turn, shaped by it through social construction of cultural characteristics. As a conclusion, this will attempt to explain what gets lost if the culture question is not properly analyzed in international relations.

\section{The Limited Role of Culture and Realism in Cold War era}

The role of culture in international relations used to be treated as a sub-topic of low politics. Within the scope of realism, which dominated to field for many years, the units

1) Yosef Lapid and Friedrich Kratochwil (eds.), The Return of Culture and Identity, (Boulder, CO: Lynne Rienner Publishers, 1997); J. Chay (ed.), Culture and International Relations, (New York: Praeger, 1990); Will Kymlicka and Baogang He (eds.), Multiculturalism in Asia, (Oxford: Oxford University Press, 2005) 
of analysis were the rationally-behaving and functionally similar states which did not happen to have cultural characteristics. The assumptions of universality and rationality that were embedded in the realist thought, and the acceptance of states as unitary actors with a determined set of interests and a specific need to maximize power to maintain survival hindered any attempt to focus on characteristics of diversity. The evolution of an epistemic community of diplomats within the umbrella of international organizations also contributed to the lack of attention given to the concept of culture.

The level of analysis debate and the structuralist emphasis on the system level as the appropriate level to focus on to get a better understanding of international relations worked to the detriment of the study of culture, which was regarded and discarded as an individual level phenomena. The structuralist approaches in the discipline of international relations did not find it necessary to look into the black box of the state let alone dwell into the level of culture. The behaviorist tendency to reach for scientific universal generalizations and the underlying laws of human behavior de-emphasized the "particular," the "different," and the "local." As international politics is defined at the level of the state and its interactions, culture is regarded as an outcome of the economic and public policies of the state, a part of the superstructure determined by the infrastructure, and unable to exert an influence on the level of politics and economy especially in the Marxist school of thought. ${ }^{2}$

As the ending of the Cold War presents us with a more fragmented world, theory of international relations is growing more aware of its own cultural roots and biases, and so it becoming more sensitive to cultural difference. Yet the scholarly discussions favored certain aspects of culture such as religion over other issues and prevented the evolution of a holistic analytical concept of culture. With the demise of Soviet Union and the bipolar world order, the need to designate "the other" resulted in the specific focus on the difference in cultures of the East and the West, the threat of Islamic fundamentalism and China and the clash of civilizations that characterized "the end of history." On the other hand, due to the globalization of international transactions, people of different cultures were faced with the necessity of negotiating and communicating with one another. This necessity emanated a range of literature from scholarly to popular writings on getting to know the other cultures and learning different negotiation styles. ${ }^{3)}$ In the meanwhile the postmodern literature emphasized

2) Gramci focused on culture as a fundamental aspect of hegemony rather than a mere product of the infrastructure. Stephen Gill. "Gramci and Global Politics: Toward a Post-Hegemonic Research," in Stephen Gill, Gramsci, historical materialism and international relations, (Cambridge: Cambridge University Press, 1993), pp.1-18. 
culture as an important factor of the promotion of diversity and relativism that lead to the acceptance of the existence of many worlds as opposed to the one world of realism and positivism. ${ }^{4}$

\section{Different Discussions of Culture}

To begin with there is no consensus as to how culture should be defined. As analyzed by Avruch and Black, anthropology proposed two different approaches to define the concept of culture. The materialist approach defines culture as the way a human group adapts to its habitat or ecosystem, while the mentalist approach regards culture as the group's creation of meaning in the world. The synthesis of these two approaches is to define culture as the consciousness through which human groups structure both their external and internal environment and physical and social world. The synthesis emphasizes the constitution of meaning to be as fundamental as the need to find shelter and food. Thus, culture embodies a shared local common sense, in other words, "assumptions and the presuppositions that individuals and groups hold about the world" concerning both their internal and external environment.

The importance of this common sense is that human beings perceive everything through the lenses of culture, which is socially structured consciousness. So, the culture determines the way people perceive and respond to the world in issue that can range from conflict behavior to culturally accepted ways of conflict resolution. However, through the complex adaptive system that enables human beings to survive in the faces of historical, ecological, economic, political or social changes, people continuously reshape and reconstitute their perceptions of reality, their creation of meaning, and the cultural norms of behavior in responding to the world perceived as such. Thus, culture, this shared local common sense about the world, both shapes and is shaped by the social interactions of the human beings in the local community. Therefore, it is both a variable and an outcome of social interactions.

3) Raymond Cohen. Negotiating Across Cultures, (Washington D.C.: USIP, 1991); Kevin Avruch, Culture and Conflict Resolution, (Washington D.C.: USIP, 1998); Michael Blacker. Japanese International Negotiating Style, (New York: Columbia University Press, 1977); Richard Solomon. Chinese Political Negotiating Behavior: A Briefing Analysis, (CA: RAND Corp., 1985); Scott Snyder. Negotiating on the Edge: North Korean Negotiating Behavior, (Washington D.C.: USIP, 1999).

4) R.B.J. Walker. One World, Many Worlds: Struggle for a Just World Peace, (Boulder, CO: Lynne Rinner, 1988). 
Defining culture as such deprives the subject matter of the simplicity many other definitions would offer. Culture in the popular sense is frequently defined as a set of rules of etiquette, customs and characteristics uniformly shared by a group of human beings. Generalization, such as "Americans are hospitable" or the Japanese 'maybe' does not mean a 'yes'" are easy to deduce but from such a definition but equally simplistic even though they may become handy for introductory conversations. At times, culture is equated with tradition or customary rules of behavior to lead to the conclusion that it is sufficient to learn the necessary rules to profess a culture. At other times, culture gains an entity and life of its own and clashes with other cultures.

These explanations on culture are not adequate since they attach a significantly high level of uniformity, rigidity, and consistency to the concept of culture, and, in doing so, limit its scope to a number of rules or several adjectives that reflect the perceived commonalities. Culture is much more profound and complex, yet less uniform and consistent as a result of its complexity. As Avruch and Black rightly express, it is important to strike a "middle ground" between universalism and particularity: cultural characteristics are not mere stylistic deviances from universal human needs, norms and behavior, however, culture does not divide the human groups into entirely unique atomistic particles but rather still present regularities and uniformities that are common to the group of human beings in question. Each individual has unique characteristics on the one hand, and commonalities with all other human beings on the other. Thus, it is important to find the middle ground and the extent to which culture contributes to the uniqueness and commonality of individual human beings in their dealing with their external and internal environment without reifying the role of culture.

\section{Culture as a Core Construct}

What makes culture so important in international relations? The first answer is that culture is one of the important constituents of a human being's identity. Northrup defines identity as "a sense of self-definition at multiple levels." Identity is the "tendency in human beings to establish, maintain and protect a sense of self-meaning, predictability and purpose." "5) Being a "core construct" in Kelly's terminology, the identity of a person shapes his/her approach to life, his/her roles, attitudes, perceptions,

5) T.A. Northrup. "The Dynamic of Identity in Personal and Social Conflict," in L. Kriesberg, eds. Intractable Conflicts and their Transformation, Syracuse, (NY: Syracuse University Press, 1989). p.63. 
behavior, and his/her sense of the self. Constituting the meaning of the world for a person, identity is a non-negotiable construct, which creates severe disturbances when changed or threatened.

Culture forms an important part of a person's identity as it determines the basis of the individual's relation to and meaning in terms of the group. As it embodies both internal and external interactions of the individual, culture serves as one of the main constructs that translates the world to the individual. At times, culture even defines the meaning and boundaries of other variables of human selfhood such as race, ethnicity and gender. Thus, a human being's perceptions, attitudes and behavior are shaped and molded by the shared local common sense that we call culture.

The significance of culture at the individual level is salient but is not its effect ameliorated in international politics through construction of impersonal entities such as the states or international organizations. This understanding may lead to a wrong answer. The conceptualization of politics to include social interactions between human beings brings forth the culture question high up on the agenda of international politics. Witnessing a penetration of the nation-state both by sub-national and transnational actors, the conflicts emanating from aspects of identity such as ethnicity, religion and race and the unfulfillment of human needs force the international relations scholars to identify the salient characteristics of the actors beyond the states themselves. The state is no longer a unitary actor but a coalition of coalitions. New actors have emerged in the international arena such as the numerous NGO's and multinational corporations. In other words, culture sets the specific local manifestations of human needs and the tools and social norms utilized to satisfy those needs. Thus identifying the unsatisfied human needs is not a sufficient response to conflict situations, one must also be able to understand, interpret and sometimes translate the culturally-specific ways conflict attitudes, perceptions and behavior manifest themselves.

In international relations, culture significantly affects: first, the process or evolution of the conflict including escalation, intractability, resolution and transformation; second, the perceptions, attitudes and conflict behavior of the parties involved; and third, the mediation or facilitation efforts. In evaluating the different effects of culture, it is important to distinguish between cross-cultural, intercultural and trans-cultural characteristics. The first set implies the differences within the same culture in time and space, and the mappings of the ethno-psychology and ethno-praxis of different parties and distinguishing the local common sense or locally deep-rooted assumptions of the groups enables one to understand the unique intricacies of the conflict. The intercultural characteristics illuminate the relations between two different cultures, and 
the trans-cultural level indicates the common themes, such as the existence of human needs that are universal among many cultures. Approaching the culture question from all three points enables the scholar to strike the middle way between universality and particularity.

\section{The Relationship between Culture and Conflict}

In terms of the evolution of conflicts, culture defines the interactions, cases and behavior that will be considered conflictual. Culture identifies "the rule of game," as it were, of what conflict is supposed to be, what constitutes one and how it is supposed to be resolved. For this reason, at many instances, a totally neutral or defensive act for one party can constitute a reason to go to war with the other. Different acts and entities embody different meanings and a certain look, sentence or even a joke may create violent opposition in one culture and none in another.

There are deep-rooted and culture-specific logic forms and culture defines the way each member understands a conflict. Culture significantly affects the way the conflict manifests itself, its rate of escalation or de-escalation, and the point, nature and extent of collusion between the parties. Basically setting the context for the human needs to manifest themselves, the local common senses profess how the individuals are supposed to deal wit instances of dissatisfaction and frustration. The deep-rooted causes of two conflicts may be the same but the ways they manifest themselves can differ from the totally non-violent responses to ferocious violence.

Culture is not a given but rather a social construction of the historical, economic, political and social hegemonies. Yet, in turn it constructs the perceptions, attitudes and the behavior of the parties to a conflict. Culture identifies the issues of contention, defines conflictural behavior and determines the culturally accepted ways of dealing with conflict. In the latter, the local common sense can profess one or several options from a menu of alternatives such as flight, accommodation, avoidance, fighting back or collaborative problem solving. ${ }^{6}$ For example, the cultural responses to the problems of immigrants can vary on a continuum that embodies denial, rationalization, situational specificity and integration. ${ }^{7)}$ The response to a conflict situation depends on the location of the conflict, the source and type of dispute, the generational outlook of the parties,

6) W. Warfield. "Factors of Race, Culture, and Ethnicity in Dispute Resolution: An NIDR Discussion Paper." The Conflict Clinic, (Fairfax, VA: George Mason University, 1990).

7) Ibid. p.3. 
length of exposure, the weight given to the issue and the level of culturally specific values and interest involved in the issue.

In regards to the culturally specific conflict perceptions, attitudes and behavior, violence can display a good example. Though violence is generally verbally condemned, certain cultural characteristics nourish its existence. Thus, for example in Korea, many NGOs condemn the use of violence, yet in many instances violence is the accepted way of resolving disputes according to the local common sense, especially when super and subordinates are in opposition. People of authority have a cultural right to perform violence despite all the efforts of the related NGOs. Communal societies based on informal relations display very different conflict resolution techniques from the individualistic, atomistic, rule-oriented societies. Thus, the conflict perceptions, attitudes and behavior become culturally and context specific, creating an environment very much opt for misperceptions and inadvertent escalation. As Northrup explains culture contributes significantly to the perception of the threat to the core constructs, the distortion or the psychological responses to the threat, the rigidification of the interpretations of the world and collusion in which the conflict becomes the definition of the self. ${ }^{8)}$

The local culture-specific logic becomes the most obvious at the negotiation table where it is confronted with that of the opponent. Even between two parties, the differences between the logics can affect the outcome of the negotiation and even contribute to the escalation of the conflict. The common sense is at many instances an unconscious, non-negotiable core construct. It is the only wary that the party can define itself, the only way the negotiators know how to give meaning to and deal with the world. Thus, it is the truth for its possessor and the opponent is wrong. Because of the unquestionable nature of this core construct, a cultural style may very well contribute to the dehumanization of the opponent since it is interpreted as an evidence of the opponent's insincerity. At this point, mediation or facilitation can contribute greatly to the resolution of the dispute by providing open communication of the needs, value, interests and bargaining positions of the parties involved.

\section{Culture in Conflict Resolution}

However, conflict resolution techniques themselves are built upon a specific cultural

8) Northrup. "The Dynamic of Identity in Personal and Social Conflict," pp.70-75. 
logic, namely that of the West. The underlying assumption in facilitation is that direct communication is desirable and should be promoted for attaining a sustainable and mutually satisfactory solution instead of settlement. In order to provide communication, facilitation sets forth obvious rules and procedures that clarify the conflict resolution process, make it predictable, prevent fear of conspiracies, maintain a concerned but neutral facilitation, decrease power gaps between the parties by providing equality and recognition to all the parties involve in the dispute. The idea behind conflict resolution is that people are capable of direct communication once the obstacles before such an act are removed and that the parties to a conflict will be able to express the profound human needs that are unsatisfied, which cause the conflict in the first place, instead of dealing with mere power bargaining at the level of position, issues and interests. The expression of these unfulfilled needs move the conflict away from the zero-sum bargaining positions and enable the parties to reach a win-win solution that will be sustainable in the long term and satisfy all the parties involved. Deep down, conflict is a rational behavior caused by the unfulfilled human needs and can be dealt with rationally. It seems that conflict resolution approach is not successful when the cultural common sense underlying its basic assumptions is overlooked.

There is a serious need to acknowledge that culture does matter, and shape the conflict resolution processes accordingly. Yet this is easier stated than done since culture can cut both ways in mediation and facilitation. On the one hand, the Western approach with its assumption of rationality is foreign to many minds. As Lederach summarizes, the modern societies are characterized by autonomous, individualistic relations, an impersonal and professional attitude towards conflict resolution, rational and formal conflict resolution techniques, and merit based evaluations of performance. Traditional societies are, on the other hand, more communal or group dependent and are characterized by the personal, relational, affective, informal, holistic networks of dealing with conflicts. $\left.{ }^{9}\right)$ Therefore, the formal, rule oriented procedures and the emphasis placed on the use of time may convey a sense of security and equity for a member of a Western culture while the same procedures can create an inhibiting impersonal environment for negotiators from more traditional cultures. According to the common sense of the parties, a facilitator may reach better results by using procedures that appeals to the cultural logic of the parties. Interpersonal communication, giving priority to people over tasks and schedules, addressing the wider social networks of the participants allowing them to maintain their formal roles in which they feel secure, and

9) J. P. Lederach. "The Mediator's Cultural Assumptions." MCS Conciliation Quarterly, (summer edition, 1986), p.2. 
providing advice and counseling when necessary even if the role of the facilitator is not to do so may contribute to the building of trust and more productive negotiations with parties coming from more traditional societies.

In his critique of western conflict resolution from a non-Western perspective, Paul Salem cites several instances where the basic presumptions of the conflict resolution approach are not compatible with the common sense of the Middle Eastern parties to a conflict. As mentioned above, war and violence are not necessarily evil for many cultures and in many instances there are higher goals or reasons that can justify and rationalize recourse to the use of force. Religion is one such factor.

Here, it is necessary to distinguish between culture and religion. Religion is the belief system concerning the meaning of existence and norms of behavior in this world and beyond. It is one of the factors that constitute culture-in many respects religion creates a culture of its own-but the difference between the culture and religion is that the latter is trans-cultural and gains its legitimacy from a divine source whereas culture is more local and is legitimized by the social consensus among the group members. Since culture embodies both the internal and the external environment of the human beings, at many instances, the local common sense is able to shape the belief systems and the practice of religion as in the case of different interpretations of Christianity and Islam. Both religion and culture can play an important role in mediation since the logic of religion can legitimize violence in the name of God and martyrdom. At other instances, even if the religions profess non-violence, the external environment can create violence-prone situations due to the building of a nation-state or territorial disputes. Religion becomes important to the extent that it shapes and formulates the construction of identity. Thus, it is equally dangerous to neglect the role of religion as a core construct as it is to interpret each dispute between parties of different religions as a fundamentally religious conflict.

There are many assumptions that a mediator or facilitator brings to the table himself/herself and these assumptions need to be acknowledged. In trying to sort out the common sense of the parties about the world in general and the conflict in particular, the mediator should evaluate his/her own unconscious assumptions. In doing so, the mediator should not assume that the parties share his/her convictions, no matter how much those assumptions are taken for granted. For example, war in itself is not shameful and is necessary in times when the status quo requires a revolution for liberation, salvation or independence, in such instances war can be "a progressive, invigorating, and purifying process." ${ }^{10)}$ The Western abhorrence of physical pain is also not shared by many other cultures where the daily life itself is composed of so much 
suffering from all aspects that physical suffering does not matter that much. Thus, the mediator's attempts to make the parties acknowledge the costs of continuing fighting may be met with resistance because the cost-benefit analysis of the cultural logic professes such costs to be bearable in the face of the higher goal.

Conflict resolution also operates upon the assumption that conflict is rational and controllable by human beings. In many cultures, conflict belongs to higher phenomena like religion or morality and is a product of fate beyond the control of human beings. Conflict involves shame, honor, and pride and is not reducible to the perceptions, attitudes, and behavior of the parties. As Salem points out, there is an important difference between negotiating for protecting what you already have and coming to the table to obtain what you do not have. The mediator or the facilitator needs to keep these in mind.

Yet, all of these critiques also have downsides. If culture sets the context and determines the tools and ways perceptions, attitudes and conflict behavior are shaped, then would not carrying on the negotiation in a culturally acceptable and comfortable way maintain, and institutionalize the conflict further? Would the parties have resorted to third parties if their common logic and ways of conflict resolution had been sufficient in the first place? How can zero-sum conflicts can be reframed in win-win terms if the way the conflict is defined and dealt with remains the same? What is the balance between accommodating culture into conflict resolution or totally rejecting it? These are questions that do not have easy answers.

It is significant to acknowledge the role of culture without reifying it. The mediator or the facilitator needs to utilize the study of how people make sense of conflictive situations and appropriate common sense methods of resolving them, to contextualize the way the parties interpret the conflict situation and their roles within the boundaries of the conflict. ${ }^{11)}$ This will help him/her to better interpret the attitudes and behavior of the parties, clarify misperceptions and translate and communicate the parties' needs, values and interests to each other. However, specific attention should be paid to the extent to which culture-specific characteristics are accommodated into the conflict resolution model so that the process of resolution does not get lost in the attempt to reach through cultural vulnerabilities. Though it is crucial to acknowledge diversity and try to understand uniqueness, it is equally important to be able to communicate one's uniqueness to others. A totally relativist and culturally-specific model of conflict

10) P.E. Salem. "A Critique of Western Conflict Resolution from a Non-Western Perspective," Negotiation Journal, (October, 1993), p.291.

11) Lederach. "The Mediator's Cultural Assumptions." p.4 
resolution may underestimate the important of finding out how similar pain, frustration and dissatisfaction of needs can be even for parties of totally different cultures.

\section{Conclusion}

If culture is not incorporated into international relations theory and practice, a fundamental understanding of the deep-rooted context of world politics will be lost. With the rapid emergence of identity conflicts that erupt into violent collisions, one needs to come to terms with low politics, where the roots of these conflicts lie. People do not go to war after detailed and rational cost-benefit analysis: rather, a mutual interaction of ideas, institutions and the world order create conflict situations. Culture plays a crucial role in setting the stage in which the dispute will take place, the nature of roles, the definition and the meaning of the conflict and the way the conflict will be carried out, escalated and resolved. However, culture is not an entity with a life of its own but rather a social construction that continuously reshaped according to the changes in the internal and external environment of the groups of human beings. Thus, culture is both a variable and outcome in international relations. As such, culture does matter and should be incorporated into international relation theory and practice in order to better understand the causes and the dynamics of conflicts, how they escalated to where they are and how they can be resolved and transformed into mutually satisfactory and sustainable outcomes for all the parties involved. 


\section{REFERENCES}

Appadurai, A., Modernity at Large: Cultural Dimensions of Globalization, (Minnieapolis: University of Minnesota Press), 1996.

Arnold, M., Culture and Anarchy, (Cambridge: Cambridge University Press), 1932.

Augsburger, David W., Conflict Mediation Across Cultures, (Louisville, KY: Westminster / John Knox Press), 1990.

Avruch, K. and P.W. Black., "The Culture Question and Conflict Resolution." Peace and Change, Vol.16-1, 1991.

Avruch, K. and P.W. Black., "Conflict Resolution in intercultural settings: Problem and prospect," in Kevin Avruch, Peter Black, and Joseph Scimecca (eds.), Conflict Resolution: Cross Cultural Perspectives, (Westport, CT: Greenwood Press), 1998.

Berton, Peter, Hiroshi Kimura, and I. William Zartman, International Negotiation: Actors, Structure/Process, Values, (New York: St.Martin's Press), 1999.

Cohen, R., Negotiating Across Cultures, (Washington, DC: U.S. Institute of Peace Press), 1991.

Chay, J. (eds.), Culture and International Relations, (New York: Praeger), 1990.

Dedring, J., "Early warning and the United Nations." Journal of Ethno-political Development, vol.4-1 (1994).

Falk, R., "The Global Promise of Social Movements: Explorations at the Edge of Time." in R. Falk, Explorations at the Edge of Time: The Prospects for World Order, (Philadelphia: Temple University Press), 1992.

Faure, G. O. and J. Z. Rubin, Culture and Negotiation, (Newsbury Park, CA: Sage), 1994.

Kimmel, P., "Cultural Perspective on International Negotiations," Journal of Social Issues, vol.50 (1994).

Kriesberg, L., "Transforming Conflicts in the Middle East and Central Europe" in L. Kriesberg, (ed.), Intractable Conflicts and their Transformation, (Syracuse, NY: Syracuse University Press), 1989.

Kymlicka, Will and Baogang He, Multiculturalism in Asia, (Oxford: Oxford University Press), 2005.

Lapid Yosef and Friedrich Kratochwil,(eds.), The Return of Culture and Identity, (Boulder, CO: Lynne Rienner Publishers), 1997.

Lederach, J.P., "The Mediator's Cultural Assumptions." MCS Conciliation Quarterly, Summer edition 2-5 (1986). 
Lederach, J.P., Preparing for Peace: Conflict Transformation Across Culture, (Syracuse, NY: Syracuse University Press), 1995.

Nadler, L.B., Marjorie Keeshan Nadler, and Benjamin J. Broome, "Culture and the Management of Conflict Situations," in W.B. Gudykunst, L. P. Stewart and S. Ting-Toomy (eds.), Communication, Culture, and Organizational Processes, (Newbury Park, CA: Sage), 1985.

Northrup, T.A., "The Dynamic of Identity in Personal and Social Conflict," in L. Kriesberg (eds.), Intractable Conflicts and their Transformation, (Syracuse, NY: Syracuse University Press), 1989.

Salem, P.E., "A Critique of Western Conflict Resolution from a Non-Western Perspective," Negotiation Journal, October. 289-297 (1993).

Starkey, Brigid, Mark A. Boyer and Jonathan Wilkenfeld, Negotiating a Complex World: An Introduction to International Negotiation, (New York: Rowman And Littlefield Publishers, Inc.), 1999.

Tomlinson, J. "Cultural Globalization and Cultural imperialism," in A. Mohammadi (ed.). International Communication and Globalization: A Critical Introduction, (London: Sage), 1997.

Touval, S., "Multilateral Negotiation: An Analytic Approach," Negotiation Journal, September. 159-173 (1989).

Vandersluis, Sarah Owen (ed.), The State and Identity Construction in International Relations, (New York: St Matin's Press), 2000.

Walker, R.B.J., "Contemporary Militarism and the Discourse of Dissent," in R.B.J. Walker (ed.), Culture, Ideology and World Order, (Boulder, CO: Westview Press), 1984.

Walker, R.B.J., One World, Many Worlds: Struggle for a Just World Peace, (Boulder, CO: Lynne Rinner), 1988.

Warfield, W., "Factors of Race, Culture, and Ethnicity in Dispute Resolution: An NIDR Discussion Paper." The Conflict Clinic, (Fairfax, VA: George Mason University), 1990.

Zartman, W. and S. Touval (eds.), "International Mediation in Theory and Practice," SAIS Papers no. 6, (Boulder, CO: Westview Press), 1985.

Zartman, W. (ed.), International Multilateral Negotiation, (Sanfrancisco: Jossey Bass), 1995. 